Supporting Information

\title{
Tuning the Adsorption of Elemental Mercury by Small Gas-Phase Palladium Clusters: First-Principles Study
}

\author{
Bulumoni Kalita
}

Department of Physics, Dibrugarh University, Dibrugarh, Assam 786004, India 
Figure S1. Several geometrical isomers of $\mathrm{Hg}$ adsorbed neutral $\mathrm{Pd}_{n}(n=1-4)$ clusters in spin multiplicities, $M=1,3$ as calculated with M06-L and B3LYP functionals.

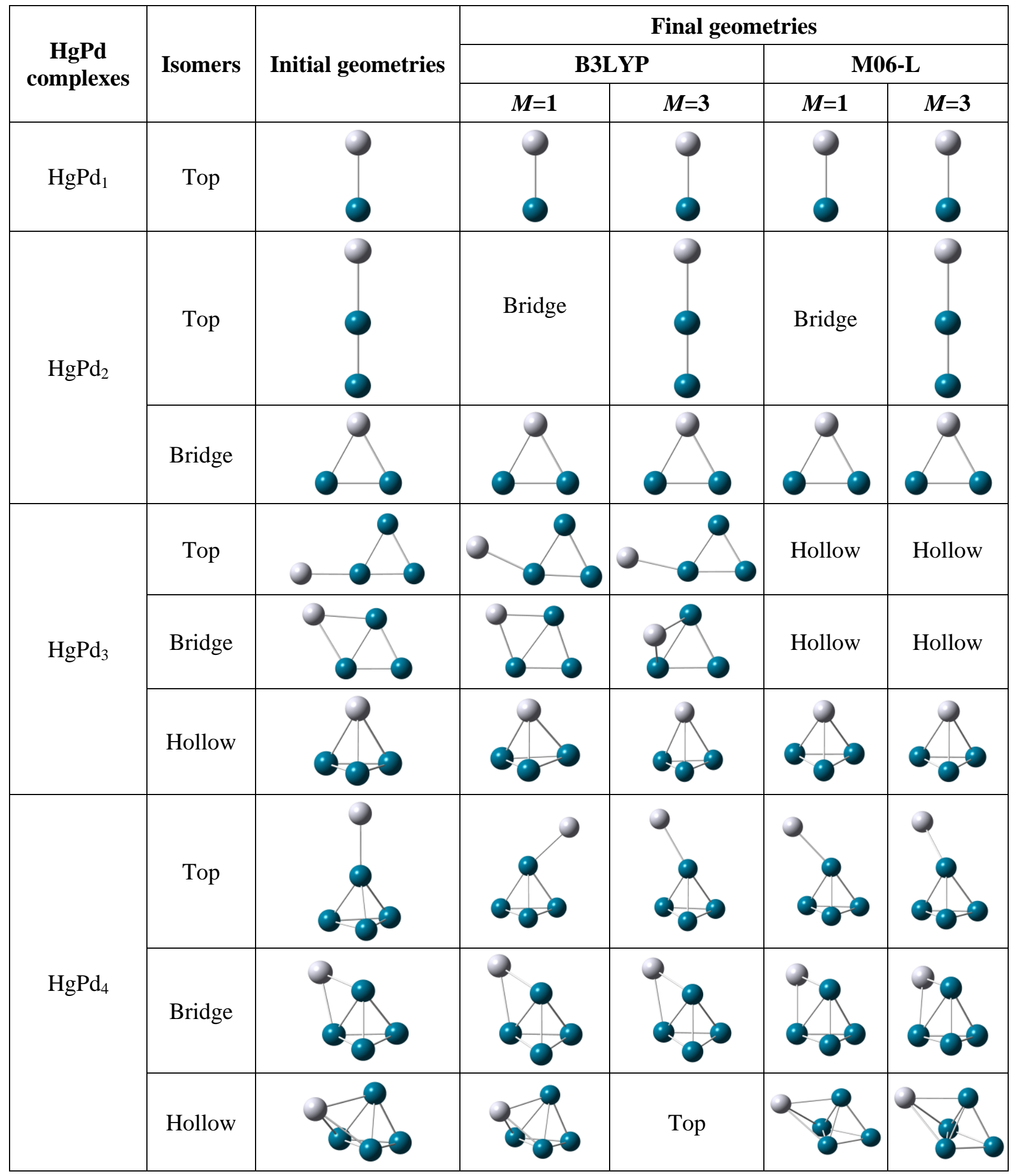


Figure S2. Several geometrical isomers of $\mathrm{Hg}$ adsorbed neutral $\mathrm{Pd}_{n}(n=5-6)$ clusters in spin multiplicities, $M=1,3$ as calculated with M06-L and B3LYP functionals.

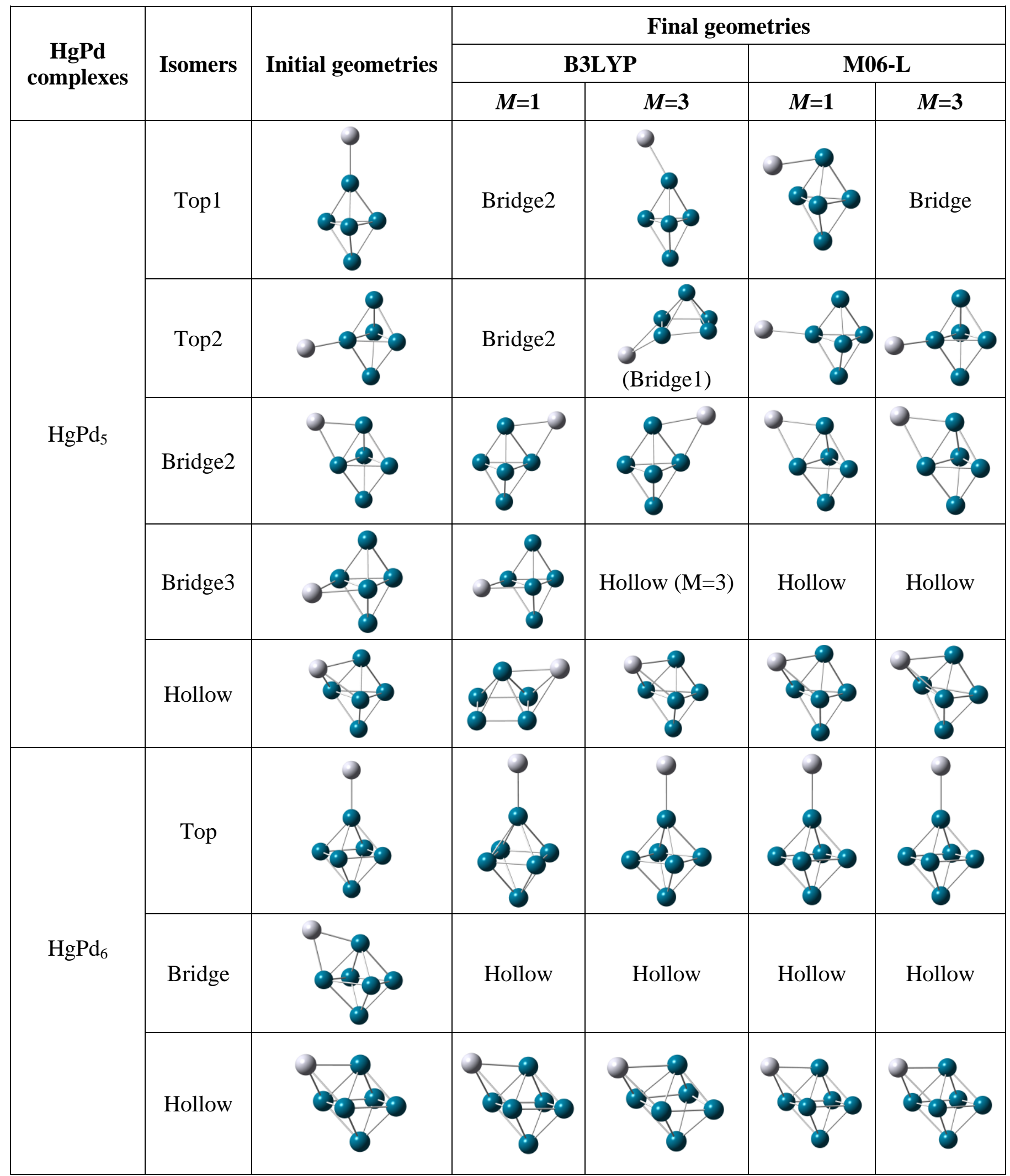


Figure S3. Variation of $\mathrm{Hg}$ binding energy with elongation of $\mathrm{Pd}-\mathrm{M}$ bond lengths in neutral $\mathrm{Hg}-\mathrm{PdM}$ complexes from those in bare $\mathrm{PdM}(\mathrm{M}=\mathrm{Pd}, \mathrm{Pt}, \mathrm{Cu}, \mathrm{Ag}, \mathrm{Au})$ dimers calculated with B3LYP and M06-L functionals.

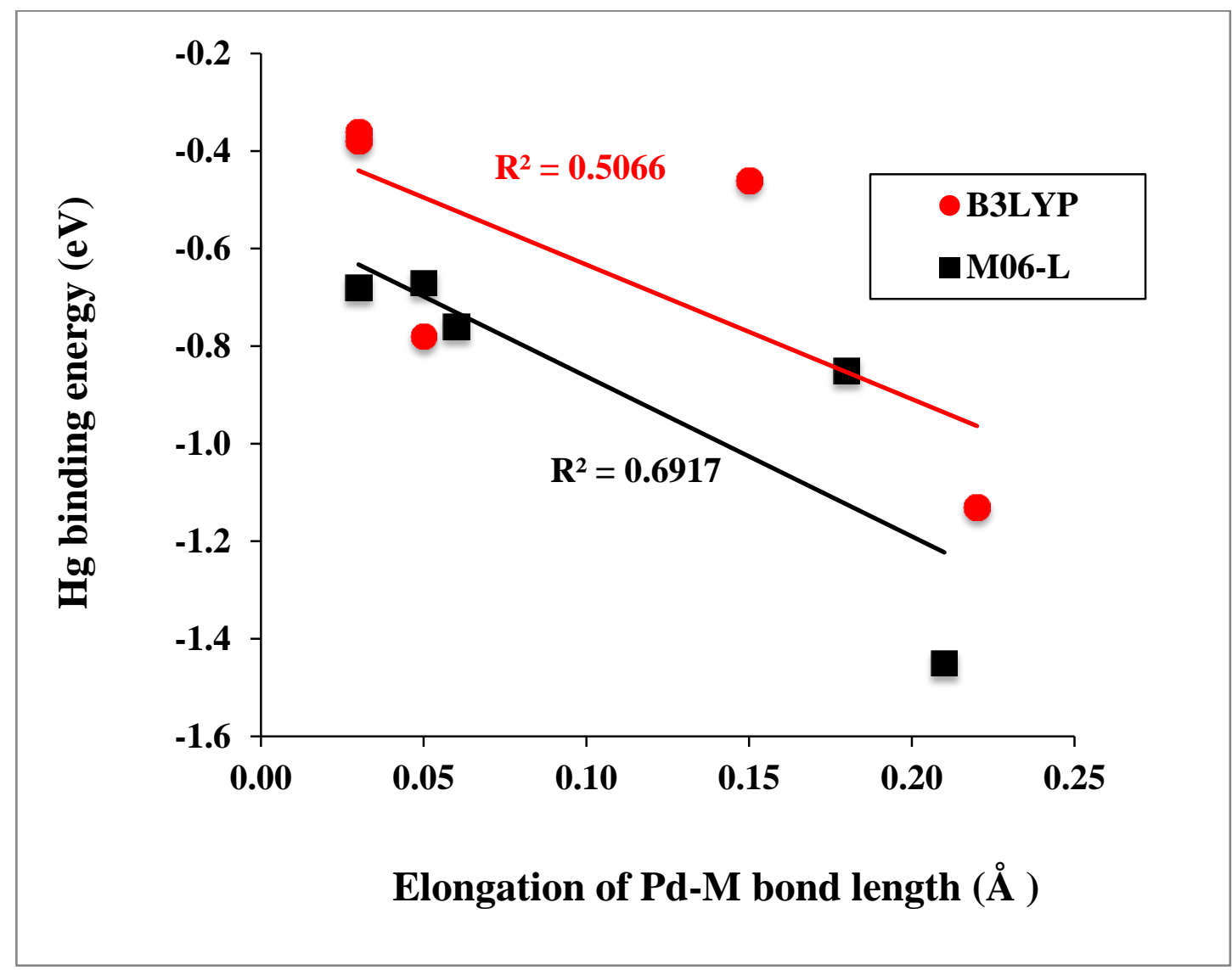


Figure S4. Variation of $\mathrm{Hg}$ binding energy with LUMO energies of cationic PdM $(\mathrm{M}=\mathrm{Pd}, \mathrm{Pt}, \mathrm{Cu}, \mathrm{Ag}, \mathrm{Au})$ dimers calculated with B3LYP and M06-L functionals.

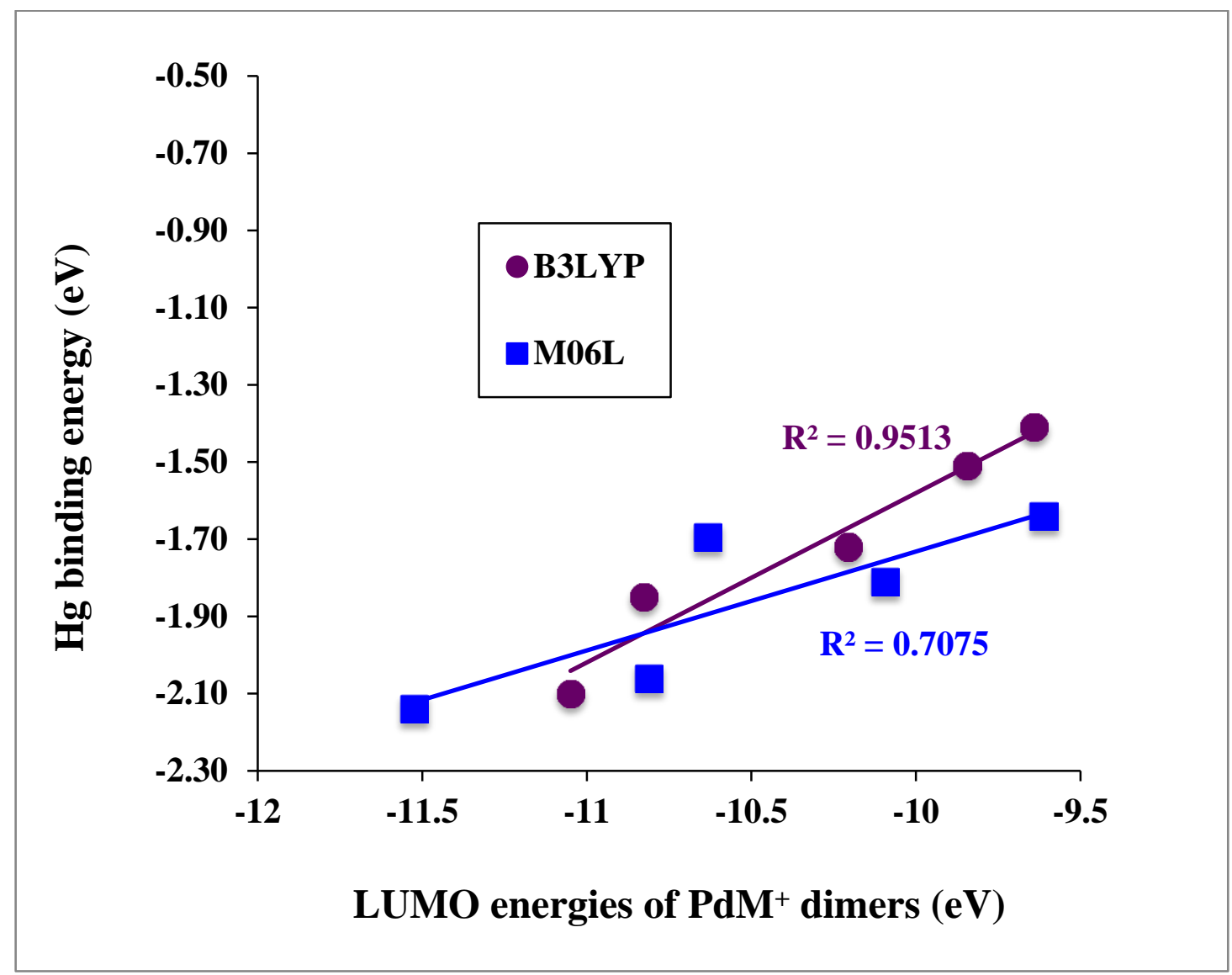


Figure S5. Variation of $\mathrm{Hg}$ binding energy with $\mathrm{NBO}$ electronic charge of $\mathrm{Hg}$ atom in cationic $\mathrm{Hg}-\mathrm{PdM}(\mathrm{M}=\mathrm{Pd}, \mathrm{Pt}, \mathrm{Cu}, \mathrm{Ag}, \mathrm{Au})$ complexes calculated with B3LYP functional.

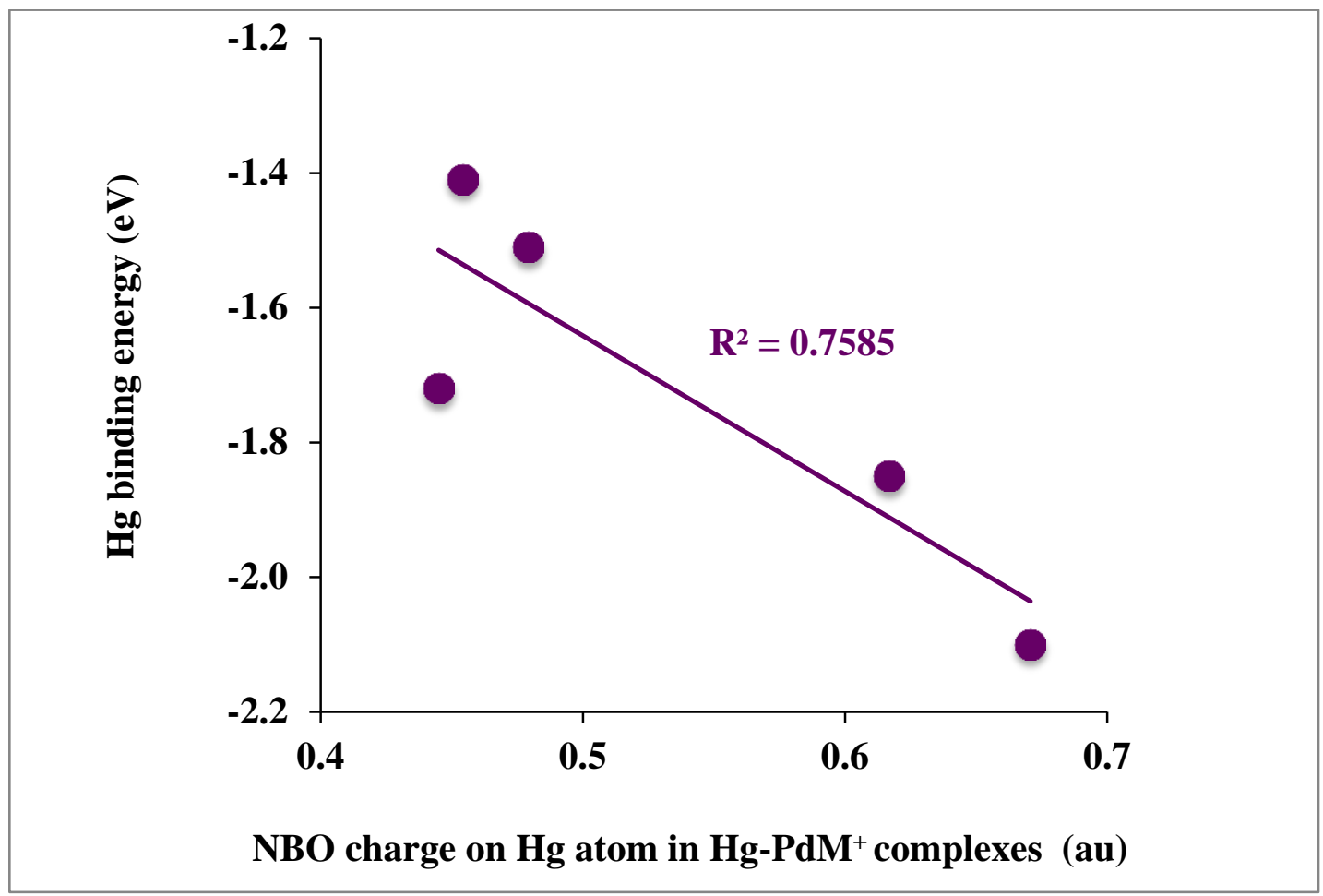


Figure S6. Variation of $\mathrm{Hg}$ binding energy with electronic charge donation from sand back-donation into d- orbitals of $\mathrm{Pd}$ atom in neutral $\mathrm{Hg}-\mathrm{PdM}(\mathrm{M}=\mathrm{Pd}, \mathrm{Pt}, \mathrm{Cu}, \mathrm{Ag}$, $\mathrm{Au})$ complexes calculated with B3LYP functional.

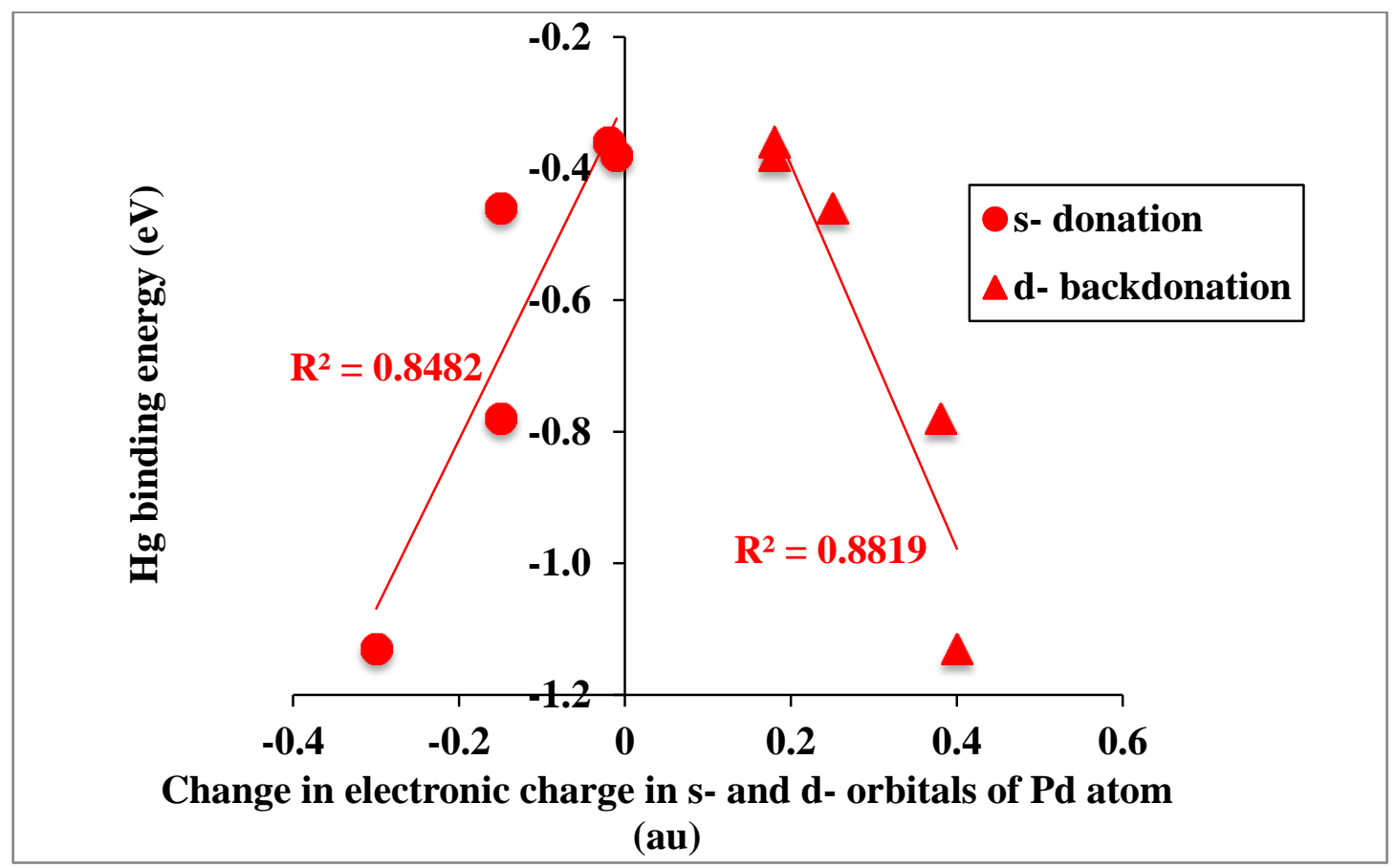

